\title{
Comissão Intergestores Regional como mecanismo de governança da política de saúde no Ceará
}

\author{
Regional Intergovernmental Commission as a governance \\ mechanism for health policy in Ceará
}

Maria Sônia Lima Nogueira ${ }^{\mathbf{1}}$ Lucia Conde de Oliveira ${ }^{\mathbf{1}}$, Liduína Farias Almeida da Costa ${ }^{\mathbf{1}}$

DOI: 10.1590/0103-1104202112901

RESUMO Canais de pactuação intergovernamental são instâncias de fortalecimento da descentralização e regionalização no Sistema Único de Saúde. A descentralização apresenta-se como importante dispositivo para a produção do poder regional. $\mathrm{O}$ artigo tem por objetivo refletir sobre a importância da Comissão Intergestores Regional na governança da saúde, na Primeira Região de Saúde do Ceará, considerando o processo de descentralização e regionalização. Trata-se de uma pesquisa social qualitativa, um estudo de caso, cujas técnicas de produção de dados foram: a entrevista semiestruturada e a observação simples. Projeto aprovado pelo Comitê de Ética em Pesquisa da Universidade Estadual do Ceará. Alguns resultados mostraram que a Comissão Intergestores Regional é uma instância importante para a governança regional da saúde, através da qual os gestores locais expressam as necessidades do município, pactuam e deliberam sobre a política de saúde da região, mostrando que não são passivos quanto às decisões pactuadas para a organização dessa área. Antes, são sujeitos que se movem em uma arena de disputa pelo melhor desenvolvimento das ações de saúde de seus munícipes, influenciando a governança desta área no estado do Ceará. Verificou-se que a Comissão Intergestores Regional é, também, um local de disputa de poder e de conflitos de interesses.

PALAVRAS-CHAVE Política de saúde. Governança. Política. Regionalização.

\begin{abstract}
The channels of intergovernmental agreement are instances of the decentralization and regionalization strengthening in the Unified Health System. Decentralization is an important device for the production of regional power. The article aims to reflect on the importance of the Regional Intergovernmental Commission in health governance in the First Health Region of Ceará, considering the process of decentralization and regionalization. It is a qualitative social research, a case study, whose techniques of data production were semi-structured interviews and simple observation. Project approved by the Research Ethics Committee of the State University of Ceará. Some results showed that the Regional Intergovernmental Commission is an important instance for regional health governance, where local managers express the needs of the municipality, agree and deliberate on the region's health policy, showing that they are not passive regarding the decisions agreed upon for the organization of this area. Prior to that, they are subjects that move in an arena of dispute for the better development of the health actions of their citizens, influencing the governance of this area in the State of Ceará. It was found that the Regional Intergovernmental Commission is also a place of dispute for power and interests, of conflicts.
\end{abstract}

1 Universidade Estadual do Ceará (Uece) - Fortaleza (CE), Brasil.

soninhaliman@gmail.com
KEYWORDS Health policy. Governance. Politics. Regional health planning. 


\section{Introdução}

A discussão sobre governança tem ocupado cada vez mais os debates políticos e acadêmicos, principalmente quando se considera a cadeia global de relações entre mercados, poderes e governos. Ela configura-se como um marco democrático na contemporaneidade, por assegurar maior coesão e interação entre estados e sociedades.

Nos anos 1990, a atenção à governança, em grande parte, foi resultado de uma crise no estado, mais precisamente de uma crise fiscal. Ela surgiu em uma perspectiva de reforma do setor público, associada ao conceito econômico de racionalidade, que abrange o neoliberalismo, a nova administração e a terceirização'.

No Brasil, essa discussão teve início no mesmo período em que se aprofundavam as reflexões sobre a descentralização política e administrativa do estado, disseminada na América Latina como uma forma específica de governar ${ }^{2,3}$. A descentralização e a regionalização realizadas no campo da saúde foram uma realidade no País, sendo a descentralização valorizada pela perspectiva de reforma do estado, por não colidir com os interesses da racionalidade econômica.

Fleury et al. ${ }^{4}$ afirmam que, com a descentralização, houve uma valorização dos secretários e dos conselhos municipais de saúde na elaboração do orçamento, o que fez declinar a influência dos políticos locais, rompendo, em parte, com o clientelismo no setor público. Nesse contexto, foram criadas a Comissão Intergestores Tripartite (CIT), a Comissão Intergestores Bipartite (CIB) e a Comissão Intergestores Regional (CIR), nos três níveis de governo, com a finalidade de subsidiar a gestão local do Sistema Único de Saúde (SUS) 3,5.

Desse modo, os canais de controle social e pactuação intergovernamental constituem-se como instâncias de fortalecimento da descentralização e da valorização da regionalização. Desde sua criação, estas instâncias têm apresentado uma aproximação com o processo de descentralização ${ }^{6}$.
A CIR, implantada de forma gradual e heterogênea ${ }^{3}$, faz parte de um arcabouço de instituições criado para viabilizar a política de saúde no Brasil. Ainda que seja uma instância de participação colegiada, não se configura como um canal de controle social com participação popular.

A implantação de um sistema nacional de saúde em um país com a dimensão territorial do Brasil é um grande desafio, principalmente quando se considera que o SUS tem se construído sem rupturas. Outro desafio é a descentralização, que satisfaz tanto a interesses econômicos quanto a políticas sociais.

Mesmo que ainda não tenham sido efetivadas em toda sua potencialidade, pelo Ministério da Saúde (MS), a descentralização e a organização dos serviços de saúde são ideias que vêm expressas desde a Constituição Federal de 1988, no artigo 198, e têm na regionalização a estratégia para sua concretização.

Sendo assim, o presente estudo justifica-se por sua importância para a gestão em saúde, pois a descentralização e a regionalização são dimensões fundamentais do SUS, enquanto campos abertos a reflexões, desde as normatizações da Norma Operacional Básica (NOB/96-SUS)7 e da Norma Operacional de Assistência à Saúde (Noas/01-SUS) ${ }^{8}$, nas quais o financiamento é repassado fundo a fundo, automaticamente, sendo criadas as instâncias gestoras CIT, CIB e CIR. O objetivo deste estudo é refletir sobre a importância da CIR na governança da saúde, na Primeira Região de Saúde do Ceará, considerando os processos de descentralização e regionalização.

\section{Material e métodos}

Parte de uma tese de doutorado em saúde coletiva, trata-se de pesquisa social qualitativa, sendo um estudo de caso. Tem suporte na pesquisa 'Organização das Redes de Atenção à Saúde no Ceará: desafios da universalidade do acesso e da integralidade da atenção', do Laboratório de Seguridade Social e Serviço 
Social da Universidade Estadual do Ceará (Lassoss/Uece), aprovada sob o parecer número 1.509.948 do Comitê de Ética em Pesquisa da Uece.

Foram utilizadas a entrevista semiestruturada e a observação simples na produção dos dados. Realizou-se, também, pesquisa documental, a partir do Plano Diretor de Regionalização9 (PDR/2006), do Plano Estadual de Saúde do Ceará10 - 2016-2019, e das Atas de Reuniões da CIR - 2012-2017.

O local da pesquisa foi a Primeira Região de Saúde do Ceará, com seus municípios: Aquiraz, Eusébio, Fortaleza e Itaitinga. As observações se realizaram durante as reuniões da CIR. Os entrevistados foram os seguintes gestores: secretários municipais e coordenadores regionais de saúde, no caso específico de Fortaleza (CE), que é dividida em 6 regionais; e servidores públicos da Secretaria da Saúde do Estado do Ceará (Sesa), que ocupavam lugar estratégico na gestão, denominados aqui de informantes-chave, totalizando 16 participantes.

Todos os sujeitos entrevistados assinaram o Termo de Consentimento Livre e Esclarecido (TCLE), sendo informados a respeito das questões éticas da pesquisa, que seguiu as orientações da Resolução $\mathrm{n}^{0}$ 466/2012 ${ }^{11}$ do Conselho Nacional de Saúde (CNS), quanto a pesquisas com seres humanos. $\mathrm{O}$ anonimato foi preservado, pois os entrevistados foram identificados por letras seguidas de um número, o que os diferenciou.

A análise dos dados foi realizada a partir do referencial analítico hermenêutico fundamentado no pensamento de Gadamer ${ }^{\mathbf{1 2}}$, segundo o qual a hermenêutica é a verdadeira arte da compreensão, entendendo que as análises consideram primeiro a interpretação dos sujeitos e depois, a reinterpretação das pesquisadoras.

Ressalte-se que a pesquisa foi financiada pela Coordenação de Aperfeiçoamento de Pessoal de Nível Superior (Capes), com a concessão de uma bolsa de Doutorado pelo período de 12 meses.

\section{Resultados e discussão}

Nos anos 1970, os governos dos países de capitalismo central enfrentaram uma crise econômica após a derrota dos 'anos dourados', desencadeando um crescente desequilíbrio fiscal, desordem nas contas públicas e inflação acelerada. Esse cenário levou à revisão do papel do estado nacional forte, protetor e centralizado. Neste contexto, surge um modelo econômico de cariz neoliberal, produzindo agendas governamentais sintonizadas com a perspectiva de maximização do mercado e minimização do Estado de Bem-Estar Social.

A adoção desse modelo pelo governo brasileiro iniciou-se ao final da década de 1980 , coincidindo com o processo de redemocratização do País, após 21 anos de gestão governamental dos militares. A expressão mais alta da redemocratização foi a promulgação da Constituição Federal de 1988, que, entretanto, deixou ampla margem para reformas. Ao final da década de 1990, ocorreu uma reforma administrativa no País, que o colocou em harmonia com a perspectiva hegemônica de governança sintonizada com uma perspectiva neoliberal.

Seguindo a perspectiva de reforma gerencial do estado, o processo de descentralização política e administrativa do Brasil passou por ressignificações, observando uma valorização da governança local. Como dizem Scatena e Tanak, "a descentralização emerge como uma estratégia - de ordem gerencial - de reestruturação do estado"13(50).

A descentralização apresenta-se, assim, como importante dispositivo para a produção do poder regional. Em estudo comparado, das políticas locais do Brasil e Angola, sobre governança e desenvolvimento local, Massuanganhe e Corralo dizem que o Brasil

[...] possui uma Constituição que empodera imensamente os municípios, que sintetiza, pela espacialidade estatal, a dimensão do poder local. Por isso, é possível discorrer sobre um verdadeiro poder municipal, desfrutado consoante o plexo de autonomias dos municípios 
brasileiros: política, auto-organizatória, administrativa, legislativa e financeira. Isso faz com que cada célula municipal disponha de condições de impulsionar o seu desenvolvimento, de forma autônoma ${ }^{14(21)}$.

No caso da saúde, os municípios devem ter uma capacidade financeira e institucional mínima para garantir a prestação de serviços básicos. E, neste quesito, a regionalização apresenta-se como um elemento fundamental, inclusive fortalecendo os consórcios entre municípios.

É necessário considerar a heterogeneidade dos municípios brasileiros, pois, se por um lado, alguns conseguem arcar com todos os níveis de complexidade da saúde de forma mais efetiva, em razão de sua organização econômica e institucional, sendo este o caso das metrópoles ou dos municípios polos, por outro, há os que têm grande dificuldade de executar suas políticas sociais, em razão da baixa arrecadação, encontrando-se nesta última situação um dos municípios pesquisados, conforme se observa no relato de um entrevistado:

[...] porque, assim, nós somos um município pobre. A arrecadação é pequena, não tem muita indústria, não tem muita empresa. A gente tem pouca arrecadação, pouca mesmo. A gente vive mais assim, a contrapartida do município é muito maior. Apesar de ter arrecadação pouca, o município tem uma contrapartida muito maior do que o Ministério da Saúde repassa pr'a gente. [A gente] anda no fio da navalha, fazendo o que pode. (GM-3).

Apesar das dificuldades e dos desafios enfrentados cotidianamente pelos municípios, a descentralização representa certa autonomia do governo regional, se comparada aos períodos de governanças anteriores, de extrema centralização.

Dessa forma, a descentralização da saúde configura-se como um processo relevante na mudança de governança do País, desde fins dos anos 1980. Não obstante as ressignificações em relação ao que foi pensado por segmentos sociais e políticos, que se empenharam na redemocratização do País, a importância da descentralização e da regionalização pode ser percebida mediante as normativas do MS, sobretudo na NOB/96-SUS7 e na Noas/01-SUS ${ }^{8}$, nas décadas de 1990 e 2000.

Vale lembrar que, com a NOB/93-SUS ${ }^{15}$, foram definidas as competências de cada esfera de governo, ficando os estados com suas funções enfraquecidas, somente retomando-as com a NOB/96-SUS7. A partir da Noas/01-SUS 8 , os estados voltaram a ter um papel importante, o de promotor da regionalização e da articulação regional, de solidariedade e responsabilidades compartilhadas. Desse modo, a Sesa teve destacada importância na condução da descentralização e da regionalização.

No contexto histórico e político-social dos anos 1990, os rearranjos quanto ao Pacto Federativo Brasileiro deram maior visibilidade às esferas federativas subnacionais, aos estados e municípios, no sentido de que estes passaram a ser os executores diretos da saúde, em razão da municipalização das políticas sociais². Isso levou à valorização dos municípios, que contou com um forte movimento de organização dos secretários municipais de saúde, levada a efeito pela reação destes mediante a desigual distribuição de recursos. Esse movimento foi potencializado pela organização e criação do Conselho Estadual de Secretários Municipais de Saúde (Cosems), em maio de 1989, seguida pelo processo de regionalização, como afirma uma entrevistada:

A municipalização de ações de serviços de saúde [...] vem acompanhada da organização dos gestores municipais, [...] foi através desse colegiado Cosems - desse processo de organização deles, que foi possível viabilizar o processo de planejamento e programação para a organização desse sistema. Quer dizer, esse processo de planejamento e de programação só foi possível em função do apoio dos secretários municipais, do envolvimento dos secretários municipais nesse processo. (IC-1). 
Conforme o relato da entrevistada, houve mobilização de gestores para organizar a descentralização da saúde, sua estruturação em espaços locais, nos municípios. Os secretários de saúde estaduais e municipais pressionaram a esfera federal e conseguiram criar uma comissão com representação de gestores de todos os níveis do governo para discutir, negociar e pactuar ações e serviços de saúde nos estados. Assim, foram criadas as comissões intergestores, importantes espaços para negociação e pactuação entre os entes federativos.

A organização dos mecanismos de indução e regulação da regionalização do SUS, concomitantemente à descentralização e à municipalização, se inicia no período de estruturação do novo projeto socioeconômico do capital, inspirado no neoliberalismo, em um ciclo político compreendido entre 1990 e 2002.

Nesse cenário, o processo de descentralização no estado do Ceará dá-se pari passu às experiências administrativas, políticas e econômicas do governo estadual da época, sintonizado com o cenário nacional, em uma clara identificação com o projeto neoliberal.

A governança do estado, sob essa perspectiva, explica o sucesso do Ceará no governo Jereissati, quanto à descentralização, já que esta coaduna com os interesses daquela perspectiva. Barbosa esclarece que

[No Ceará] a descentralização, com transferência de serviços para os municípios, tornou-se prioritária a partir de 1987. O Ceará foi o Estado do Brasil que mais rapidamente e amplamente municipalizou a saúde 16(194)

Ressalte-se que o Ceará tem sido pioneiro na organização da saúde em momentos específicos de sua história, a exemplo da valorização do trabalho da comunidade com a experiência exitosa do Programa Agentes de Saúde (PAS), que motivou o MS a criar o Programa Agente Comunitário de Saúde (Pacs), em 1991, considerando como fator importante a supervisão do trabalho dos agentes, pela enfermagem ${ }^{17}$. Também na regionalização da saúde, quando o estado já caminhava rumo à organização desse processo com a experiência de Baturité, em 1998, e somente em 2001, o MS lançou a Noas/01-SUS como o instrumento normativo da regionalização. Outro exemplo são os consórcios verticais de saúde formados entre o estado e os municípios logo após a aprovação da Lei $n^{\circ} 11.107$, de 2005, experiência cearense que serviu de base para a implantação de consórcios também na Bahia ${ }^{\mathbf{1 8}}$.

O Ceará antecipou-se à Noas/01-SUS no processo de regionalização, organizando o sistema de saúde em microrregiões, em 1998. A Sesa coordenou o projeto-piloto de implantação de sistemas microrregionais e sistemas integrados de serviços de saúde, contando com expressiva participação de gestores municipais, profissionais de saúde e lideranças políticas. Esta experiência do Ceará, então, serviu de base para a Noas/01-SUS ${ }^{19}$.

A regionalização do sistema de saúde cearense foi composta, inicialmente, de três macrorregiões (Fortaleza, Sobral, Cariri). Posteriormente, em 2014, houve uma reorganização, resultando em 5 (Fortaleza, Sobral, Cariri, Sertão Central e Litoral Leste/Jaguaribe), com 22 microrregiões de saúde, atualmente chamadas de Áreas Descentralizadas de Saúde (ADS).

A organização dos serviços de saúde, a partir da regionalização, exigiu que fossem criados instrumentos de gestão capazes de viabilizar o desenvolvimento dessa política, destacando-se a CIB e a CIR, responsáveis pela discussão e pactuação entre estado e municípios.

A CIR foi instituída nas regiões de saúde pelo estado, articulada aos municípios, considerando as diretrizes gerais pactuadas na CIT. Realiza estudos para subsidiar as discussões e pactuações no SUS, na ADS20.

A criação desses espaços de negociação entre gestores de âmbitos distintos (União, estados e municípios) dá-se em 1991. Inicialmente, foi criada a CIT, com atuação nacional. Entre os anos 1993 e 1995, vieram as CIB, com representantes do estado e dos municípios, com a função de elaborar propostas para uma gestão 
descentralizada do SUS. A criação da CIR se deu com o Decreto $n^{0} 7.508 / 2011^{21}$, em substituição ao Colegiado de Gestão Regional (CGR), expresso no Pacto pela Saúde de $2006^{22}$.

Essas instâncias de negociação, que não têm participação direta da população, reportam às reflexões de Avritzer ${ }^{23}$ sobre instituições participativas e desenho institucional, cujas direções de participação seriam antecipadas: a) de baixo para cima; b) com desenho de partilha; e c) com ratificação pública, em que não há participação da sociedade.

Guardadas as devidas proporções, ficam as questões: por que não há participação da sociedade nessas instâncias? É possível compreender que tal participação se faz via conselhos de políticas públicas, antecipadamente? A resposta obtida a partir de um técnico da Sesa foi que o Conselho Estadual de Saúde (Cesau) é o espaço em que a sociedade civil tem acento, sendo as comissões intergestores de saúde espaços de diálogo entre gestores, tendo funções diversas das instâncias de controle social.

Embora as comissões intergestores não sejam do tipo que têm a participação direta da sociedade civil, ainda pode-se dizer que são espaços de participação, mesmo que só tenham a representação dos gestores na medida em que tratam de assuntos de interesse da população e que são, em última instância, discutidas no Cesau. Ainda que não haja uma relação direta entre comissões e Cesau na definição de suas pautas, elas coincidem muitas vezes. Mesmo assim, não se visualizou uma participação do conselho nas reuniões da CIR, situação diferente da encontrada no estudo de Pereira ${ }^{24}$, no qual os conselhos de saúde de algumas regiões têm participação ativa em tais reuniões.

Se as comissões envolvem apenas a participação da sociedade política, não cabendo em sua estrutura a participação da sociedade civil, elas podem ser inseridas no terceiro desenho institucional de Avritzer ${ }^{23}$, o da 'ratificação pública', em que não há a participação da sociedade, o que de modo algum diminui sua importância.
A CIR-Ceará é definida em seu regimento interno como

[...] foro permanente de negociação e pactuação entre gestores estaduais e municipais para a operacionalização das políticas públicas de saúde no âmbito regional, observando a legislação vigente que rege o sistema de saúde ${ }^{5(1)}$.

Trata-se de um espaço potente para governança regional ao constituir-se como canal permanente e contínuo de negociação e decisão entre municípios e estado, e por estarem mais próximas das necessidades dos usuários da saúde ${ }^{5}$.

Os gestores locais têm papéis relevantes na CIR por conhecerem as condições de saúde dos municípios. Fleury et al. ${ }^{4}$ destacam a importância da gestão local da saúde, como também sua influência na definição das políticas regionais desta área, por meio dos canais de governança fazendo parte do arcabouço do SUS ao pactuarem e negociarem estratégias para tal governança e prioridades entre os três níveis de governo, bem como para fortalecer a gestão regional da saúde.

Um estudo ${ }^{25}$ apontou que, no Ceará, há uma institucionalidade avançada, no que concerne ao desenvolvimento desses canais, e que, na organização da política de saúde, referente ao processo político e às relações intergovernamentais, o estado se sobressai entre muitos outros do País. Os autores caracterizam a CIB como uma instância de cooperação interativa, com uma capacidade de atuação elevada, o que favorece tal organização política.

Os municípios do estudo têm portes socioeconômicos diferentes, possuem sistemas de governança locais com capacidades financeira, administrativa e operacional de serviços de saúde diversas, que impactam na oferta de serviços. Os de pequeno porte não podem ofertar todos os serviços por questões de economia de escala. Sua baixa arrecadação impossibilita a oferta de serviços de saúde mais complexos. Considerando essas realidades, a regionalização foi organizada em consonância 
com a descentralização. Cada município deve ofertar serviços de acordo com sua capacidade resolutiva, devendo todos ofertar, no mínimo, atenção primária.

O perfil sociodemográfico dos municípios estudados apresentou grande disparidade, sendo que, nos dois extremos estão os municípios de Itaitinga (CE) - o mais pobre, com menores arrecadação fiscal e Índice de Desenvolvimento Humano (IDH), e com mais dificuldades para responder às demandas de saúde da população - e o de Fortaleza (CE) - município-polo, que agrega em torno de si uma gama de ofertas de serviços de saúde em todos os níveis, mas, insuficientes para atender sua população e as referências dos demais municípios que constituem a ADS.

A descentralização tem demonstrado potencialidades no SUS: fortalecimento da esfera municipal na condução dos serviços de saúde; pactuação política entre União, estados e municípios, superando a centralização político-administrativa; retomada da regionalização como eixo central da política de saúde, em que atualiza os instrumentos de planejamento expressos na Noas/01-SUS; e criação dos mecanismos de pactuação e decisão intergovernamental, como a CIR, valorizando e fortalecendo a governança regional da saúde.

Embora a CIR seja uma instância de representação de gestores, as demandas da Sesa ou as determinadas a partir do MS, anunciadas e tratadas conforme identificado nas pautas de reuniões, possuem relevância para os municípios em questão, pois se sintonizam com suas necessidades.

As observações realizadas nas reuniões favoreceram a compreensão da atuação dos sujeitos que ali se encontravam para contribuir com a gestão da política de saúde do estado, a partir de demandas e condições concretas do município.

Em uma das reuniões, foram apresentados, pelos técnicos da Sesa, dois pontos de pauta: o Projeto QualificaAPSUS e a Programação Geral de Ações e Serviços de Saúde (PGASS), sendo esta um "instrumento de fortalecimento da governança regional, na medida em que se propõe a sistematizar os pactos entre os gestores das três esferas de governo"26(3).

Foram observadas as inquietações dos participantes quanto à nova demanda do MS dada aos municípios. Apesar de uma maior autonomia adquirida por estes, com a descentralização, percebe-se, ainda, uma forte determinação do nível central na orientação da política de saúde, isto porque a função do poder central na saúde é a de formulação de políticas, enquanto a do município é, sobretudo, a execução de serviços.

As reuniões da CIR configuram-se como importantes espaços de discussões e deliberações de temas relevantes para o SUS, com destacada significação para os gestores municipais de saúde, quanto à descentralização e à regionalização, pois discutem temas e situações específicas das realidades locais. Todas as discussões acerca do processo de organização da rede de saúde, de protocolos de fluxo e de pactuação de serviços entre os municípios da região se dão na CIR, que tem um papel muito importante, segundo um entrevistado:

\section{A rigor, essas instâncias do SUS [CIB e CIR], todas elas são muito importantes porque elas são, de certa forma, como uma arena onde os atores par- ticipam, discutindo sobre os problemas daquela região, né? [...] Elas aproximam os municípios, fazem dialogar com esses atores, no sentido de solucionar os problemas da saúde naquele âmbito territorial. (GM-2).}

Para Fleury et al. ${ }^{4}$, os gestores municipais têm grande influência na definição das políticas regionais de saúde, através dos canais de governança, ao pactuarem e negociarem estratégias e prioridades entre estado e municípios, além de fortalecerem a gestão regional da saúde. Refletem que a CIR é fundamental para a governança regional porque cria um canal permanente e contínuo de negociação e decisão entre os municípios e o estado, valorizando a governança regional. 
A governança pressupõe organização. $\mathrm{O}$ conceito de organização abrange, segundo Mário Testa, dois aspectos:

o institucional e o agrupamento de pessoas com interesses comuns, os atores sociais primários. É nas organizações nesse duplo sentido que está situado o poder da sociedade 27(117).

O corpo institucional da política pública de saúde é formado por unidades de saúde e órgão colegiado, além de pela Sesa e entidade a ela vinculada. As comissões intergestores e os conselhos constituem espaços com forte presença institucional e declarada disputa de poder em torno das deliberações. A CIR pesquisada tem os dois aspectos: o institucional e de um agrupamento de pessoas com interesses comuns.

Na CIR estão presentes relações de poder que definem os rumos da saúde da região. Há uma íntima relação entre poder e governança da saúde no SUS, sendo esta configurada mediante um conjunto de ações do estado, o qual é formado, segundo Bourdieu, por:

[...] um conjunto de recursos específicos que autorizam seus detentores a dizer o que é certo para o mundo social em conjunto, a enunciar o oficial e a pronunciar palavras que são, na verdade, ordens, porque têm atrás de si a força do oficial28(85).

Na CIR são debatidas e deliberadas questões referentes à prestação de serviços, às responsabilidades dos municípios, bem como aos indicadores de saúde. No estado, o poder é exercido pelos seus agentes. No caso da CIR da Primeira Região de Saúde, o poder circula entre os secretários municipais e a presidente da comissão, aos quais compete deliberar sobre as demandas e legitimá-las.

Sendo a CIR um espaço de governança importante, o exercício do poder é atravessado por disputas, embates e conflitos, e não por harmonia. Nela, os gestores locais expressam seu poder de decisão, ainda que relativo, pois são guiados pelo comando único do MS, como se observa em um relato:

Com relação à participação da Comissão, o que tem hoje que a gente [decide] é o município que inicia e tenta se resolver. Nunca vai na CIR, pra CIR aprovar, pra depois a gente começar. Não tem esse apoio de começar, de estruturar [por parte da Sesa], não. A gente já faz e vai só pra eles oficializarem uma coisa que já decidiu ser feita [...] Nós decidimos como fazer da melhor forma. O importante pra eles é a gente fazer, responder aos indicadores. (GM-4).

Quando um gestor diz que decide fazer algo sem que o nível central determine, antes mesmo de receber um comando da Sesa, é porque esses sujeitos (gestores) executam os serviços baseados em uma competência e uma necessidade que são próprias do gestor local. Sua função é cumprir as determinações da política nacional de saúde, mas considerando as especificidades locais. Tomam decisões a partir do conhecimento da realidade local, das necessidades dos municípios, tornando sua atuação mais que procedimental.

A governança da saúde envolve relações de poder, sendo tensionada, o tempo todo, pela interação entre os sujeitos envolvidos na organização da política do estado, expressa nas reuniões da CIR, como referido. Estas reuniões configuram-se como locais onde há dissensos e consensos ${ }^{29}$, são tanto locus de negociação como de conflitos, que surgem em razão dos diversos assuntos ali discutidos. Os tensionamentos se dão em razão dos interesses ali representados. Situação semelhante foi apresentada no estudo de Pereira ${ }^{24}$, ao citar o exemplo da pactuação de recursos e de cirurgias eletivas como uma das causas de conflito.

O poder é disseminado em toda a sociedade, é relacional ${ }^{30}$, está presente na relação entre os sujeitos representados na CIR, independentemente do nível de gestão. Assim, ele está na relação do estado com os municípios, que entendem que não têm suas necessidades atendidas plenamente, sendo necessárias as pactuações, sobretudo em razão do financiamento, visto que há municípios com arrecadação muito 
baixa e que se sentem cobrados, pelo poder central, a cumprirem procedimentos.

Mesmo que haja um comando do nível central, os gestores regionais possuem o poder de decisão em relação à forma de implementação dos serviços. São eles que organizam a demanda de saúde de seus municípios, não estando submetidos a determinações do nível central, na perspectiva do cumpra-se sem nenhuma consideração da situação local, respeitando as determinações contidas nos Pactos pela Saúde de $2006^{22}$. Essa foi uma das questões mais tensas observadas e constatadas no estudo.

Fleury et al. ${ }^{4}$ referem-se à importância da gestão local na organização da saúde e à influência dos gestores regionais na definição das políticas regionais de saúde, via mecanismos de governança como a CIR. As normas e portarias do SUS explicitam a importância e o papel de cada esfera de gestão da saúde. Sua regulamentação, através da Lei no ${ }^{0} .080 / 90^{31}$, capítulo IV, apresenta as competências e as atribuições de cada esfera de gestão, indicando a autonomia e o protagonismo do nível municipal na organização do SUS.

Em relação ao resultado do processo de descentralização, quanto às esferas federal e municipal, cabem ações diferentes em termos de política de saúde. Assim, a instância nacional é a detentora do poder regulatório com comando único, mas cada esfera de governo tem sua autonomia instituída, a partir da descentralização, ainda que sejam interdependentes no comando da saúde. Neste sentido, ao âmbito federal cabe normatizar (criar leis e normas), formular a política de saúde, criar a agenda nacional de saúde para todo o território, com as grandes bases para garantir a unidade do sistema, e induzir políticas, por meio de incentivos financeiros. Algumas atribuições são concorrentes, outras, compartilhadas com os três níveis de governo. Aos estados e municípios é enfatizada a execução dos serviços ${ }^{30}$.

Às instâncias federativas subnacionais cabe muito mais que uma governança, que poderia chamar-se apenas de operacional ou procedimental, uma vez que a gestão municipal participa tanto do planejamento quanto da programação e da organização da rede regionalizada de saúde, bem como da execução. Os gestores não apenas fazem acordos sobre procedimentos que já vêm determinados desde o nível central, para operacionalizá-los no âmbito regional, sem nenhuma consideração da realidade local. $\mathrm{O}$ que se observa é que há uma excessiva normatização e incentivos financeiros insuficientes, estreitando a autonomia dos municípios para inovarem no planejamento.

Observou-se, com as determinações do MS e da Sesa (pautas PGASS e QualificaAPSUS), que os gestores se organizavam e discutiam como cada município faria sua adequação a essas demandas do nível central, e que, antes de tudo, essas seriam demandas da sociedade, carecendo necessariamente de discussão e deliberação nos conselhos de saúde.

Tendo em vista a perspectiva relacional do poder ${ }^{30}$, observa-se que os gestores locais não são passivos, quanto às decisões pactuadas para a organização da saúde. Ao pactuar e estabelecer relações com outros municípios, e diálogos com outros gestores, os secretários municipais de saúde estão exercendo seu poder de organização local dessa área. Situação esta também observada nas reuniões da CIR, especialmente nos diálogos entre secretários, para além das pactuações oficiais.

Essas relações de poder estabelecidas no âmbito do estado destacam os gestores locais como sujeitos que se movem em uma arena de disputa pelo melhor desenvolvimento das ações de saúde para seus munícipes, influenciando a governança da saúde no estado do Ceará, pois é no município que são executados os serviços que, efetivamente, têm resultado na vida das pessoas, o que não nega a importância do âmbito estadual na condução da política.

\section{Considerações finais}

O estudo mostrou a CIR como um importante canal de comunicação entre gestores, para discutir e pactuar questões relativas à organização 
do SUS, chegando a decisões que se dão por consenso através de votações.

Tanto os documentos (Atas de Reuniões) consultados quanto as entrevistas indicaram a CIR como um mecanismo potente de governança regional da saúde no Ceará, ainda que eivada de relações de poder, justamente porque ali estão representados diversos interesses, sendo o poder das esferas regionais limitado em razão de suas atribuições definidas em leis e portarias, fazendo parecer que detém apenas a função de cumprir o que vem determinado desde o nível central.

As relações de poder estabelecidas entre os sujeitos que discutem os rumos da saúde na Primeira Região definem a governança da saúde no Ceará e demonstram a autonomia relativa dos gestores regionais, que, ainda assim, são capazes de imprimir transformações no SUS, no contexto local, que ultrapassam ou se antecipam às determinações do nível central, como foi o caso da criação do PAS, da organização do processo de regionalização no Ceará, iniciado antes das normativas ministeriais, e da implantação de consórcios entre municípios cearenses.

Mesmo que a CIR não tenha uma relação direta com os canais de controle social representantes da população, como conselhos de saúde, ela é a condutora do processo de organização da saúde nos municípios, envolvendo a descentralização e a regionalização, bases sobre as quais se organiza a política de saúde no estado.

Sem a pretensão de esgotar o assunto, o presente estudo apenas chama à reflexão sobre a discussão em torno da importância da CIR na governança da saúde, a partir dos processos de descentralização e regionalização. Os principais achados, como a importância da CIR para a governança da saúde, a relação de poder que se estabelece entre os sujeitos nas reuniões da CIR e os conflitos ali presentes não significam que este assunto tenha sido encerrado pela presente pesquisa. Ao contrário, há lacunas neste estudo que outros olhares possivelmente identificarão e poderão sanar, futuramente, contribuindo no processo de produção do conhecimento.

\section{Colaboradoras}

Nogueira MSL (0000-0002-1699-907X)* e Costa LFA (0000-0003-3674-8195)* contribuíram para a elaboração do texto como um todo, análise e interpretação dos dados, revisão crítica do conteúdo e aprovação da versão final do manuscrito. Oliveira LC (0000-0001-82657476)* contribuiu para a orientação da pesquisa, revisão crítica do conteúdo e aprovação da versão final do manuscrito. 


\section{Referências}

1. Bevir M. Governança democrática: uma genealogia. Revista de Sociologia e Política [internet]. 2011 [acesso em 2017 abr 2]; 19(39):103-114. Disponível em: http:// www.scielo.br/pdf/rsocp/v19n39/a08v19n39.pdf.

2. Pereira AMM, Lima LD, Machado CV. Descentralização e regionalização da política de saúde: abordagem histórico-comparada entre o Brasil e a Espanha. Ciênc. Saúde Colet. 2018; 23(7):2239-2251.

3. Albuquerque MV, Lima LD, Oliveira RAD, et al. Governança regional do sistema de saúde no Brasil: configurações de atores e papel das Comissões Intergovernamentais. Ciênc. Saúde Colet. 2018 [acesso em 2020 nov 21]; 23(10):3151-3161. Disponível em: https://www. scielosp.org/article/ssm/content/raw/?resource_ ssm_path=/media/assets/csc/v23n10/1413-8123csc-23-10-3151.pdf.

4. Fleury S, Ouverney ALM, Kronemberger TS, et al. Governança local no sistema descentralizado de saúde no Brasil. Rev Panam Salud Publica. 2010 [acesso em 2020 maio 24]; 8(6):446-455. Disponível em: http://www.scielosp.org/scielo.php?script=sci_artte xt\&pid=S1020-49892010001200006.

5. Ceará. Resolução n ${ }^{0} 122$, 9, maio 2014. Regimento Interno da Comissão Intergestores Regional. Diário Oficial do Estado do Ceará. 11 Fev 2015.

6. Carvalho G. A inconstitucional administração pós-constitucional do SUS através de normas operacionais. Ciênc. Saúde Colet. 2001; 6(2):435-444.

7. Brasil. Ministério da Saúde. Portaria n ${ }^{0} 2.203$, de 05 de novembro de 1996. Estabelece a Norma Operacional Básica da Saúde. Diário Oficial da União. 6 Nov 1996.

8. Brasil. Ministério da Saúde. Portaria n ${ }^{\circ}$ 95, de 26 de janeiro de 2001. Estabelece a Norma Operacional de Assistência à Saúde. Diário Oficial da União. 29 Jan 2001.
9. Ceará. Secretaria Estadual de Saúde do Ceará. Plano Diretor de Regionalização. 2001.

10. Ceará. Secretaria Estadual de Saúde do Ceará. Plano Estadual de Saúde 2016-2019. [acesso em 2020 maio 18]. Disponível em: https://www.saude.ce.gov.br/wp-content/uploads/sites/9/2018/06/plano_estadual_ de_saude_2016_2019.pdf.

11. Conselho Nacional de Saúde. Resolução no ${ }^{\circ} 466$, de 12 de Dez 2012. Diretrizes e normas regulamentadoras de pesquisas envolvendo seres humanos. Diário Oficial da União. 13 Jun 2013.

12. Gadamer HG. Verdade e método I: traços fundamentais de uma hermenêutica filosófica. 2. ed. Petropólis: Vozes; 2002.

13. Scatena JHG, Tanak YO. Os instrumentos normalizadores no processo de descentralização da saúde. Rev. Saúde Soc. 10(2):47-74.

14. Massuanganhe IJ, Corralo GS. Governança democrática e desenvolvimento local: uma perspectiva comparada das políticas locais do Brasil e Angola. Justiça do Direito. 2014; 28(1).

15. Brasil. Ministério da Saúde. Portaria $n^{\circ} 545$, de 20 de maio de 1993. Estabelece a Norma Operacional Básica do Sistema Único de Saúde - NOB-SUS/93. Diário Oficial da União. 20 Maio 1993.

16. Barbosa JPA. Saúde e poder: uma história das instituições de saúde pública do Estado de Ceará. Fortaleza: RDS; 2017.

17. Viana ALD, Dal Poz MR. A Reforma do Sistema de Saúde no Brasil e o Programa de Saúde da Família. Physis: Rev. Saúde Colet. 2005; 15(supl):225-264.

18. Julião KS, Olivieri C. Cooperação intergovernamental na política de saúde: a experiência dos consórcios públicos verticais no Ceará, Brasil. Cad. Saúde Pública. 2020; 36(3):01-12. 
19. Barbosa JPA. Sistemas integrados de serviços de saúde: a reforma microeconômica dos sistemas de serviços de saúde no Brasil. Belo Horizonte: Mimeo; 1999.

20. Silveira Filho RM, Santos AM, Carvalho JÁ, et al. Ações da Comissão Intergestores Regional para gestão compartilhada de serviços especializados no Sistema Único de Saúde. Physis Rev. de Saúde Coletiva. 2016 [acesso em 2020 nov 22]; 26(3):853-878. Disponível em: https://www.scielosp.org/pdf/physis/2016. v26n3/853-878/pt.

21. Brasil. Decreto $n^{0} 7.508$, de 28 de junho de 2011. Regulamenta a Lei $\mathrm{n}^{\circ} 8.080$, de 19 de setembro de 1990, para dispor sobre a organização do Sistema Único de Saúde, o planejamento da saúde, a assistência à saúde e a articulação interfederativa, e dá outras providências. Diário Oficial da União. 28 Jun 2011.

22. Brasil. Ministério da Saúde. Portaria no 339 de 22 de fevereiro de 2006. Divulga o Pacto pela Saúde 2006 - Consolidação do SUS e aprova as Diretrizes Operacionais do Referido Pacto. Diário Oficial da União. 22 Fev 2008.

23. Avritzer L. Instituições participativas e desenho institucional: algumas considerações sobre a variação da participação no Brasil democrático. Opin. Pública. 2008 ; 14(1):43-64.

24. Pereira VOM, Shimizu HE, Ramos MC, et al. Regionalização em saúde em Minas Gerais: uma análise da percepção dos representantes de Comissões Intergestores Regionais. Physis: Rev. Saúde Colet. 2020; 30(1):1-23.
25. Machado CV, Lima LD, Viana ALD, et al. Federalismo e política de saúde: comissões intergovernamentais no Brasil. Revista de Saúde Pública. 2014 [acesso em 2015 set 1]; 48(4):642-650. Disponível em: http://www.scielo.br/pdf/rsp/v48n4/pt_00348910-rsp-48-4-0642.pdf.

26. Brasil. Ministério da Saúde. Portaria $n^{0}$ 1.631, de 01 outubro de 2015. Aprova critérios e parâmetros para o planejamento e programação de ações e serviços de saúde no âmbito do SUS. Diário Oficial da União. 2 Out 2015

27. Testa M. Pensar em saúde. Porto Alegre: Artes Médicas; 1992.

28. Bourdieu P. Sobre o Estado: cursos no Collège de France (1989-92). São Paulo: Companhia das Letras; 2014.

29. Bobbio N. O futuro da democracia: uma defesa das regras do jogo. 6. ed. Rio de Janeiro: Paz e Terra; 1986.

30. Foucault M. A microfísica do poder. Rio de Janeiro: Graal; 2012.

31. Brasil. Lei ${ }^{\circ}$ 8.080, de 19 de setembro de 1990. Lei Orgânica da Saúde. Diário Oficial da União. 20 Set 1990.

\footnotetext{
Recebido em 10/08/2020

Aprovado em 07/12/2020

Conflito de interesses: inexistente

Suporte financeiro: o presente trabalho foi realizado com apoio da Coordenação de Aperfeiçoamento de Pessoal de Nível Superior Brasil (Capes) sob o Código de Financiamento 001
} 